University of Wollongong

Research Online

Faculty of Social Sciences - Papers (Archive) Faculty of Arts, Social Sciences \& Humanities

$1-1-2013$

Connection, challenge, and change: the narratives of university students mentoring young Indigenous Australians

\author{
Sarah O'Shea \\ University of Wollongong, sarah.oshea@curtin.edu.au \\ Valerie Harwood \\ University of Wollongong, vharwood@uow.edu.au \\ Lisa Kervin \\ University of Wollongong, lkervin@uow.edu.au \\ Nici Humphry \\ University of Wollongong, nrh707@uowmail.edu.au
}

Follow this and additional works at: https://ro.uow.edu.au/sspapers

Part of the Education Commons, and the Social and Behavioral Sciences Commons

Research Online is the open access institutional repository for the University of Wollongong. For further information contact the UOW Library: research-pubs@uow.edu.au 


\title{
Connection, challenge, and change: the narratives of university students mentoring young Indigenous Australians
}

\author{
Abstract \\ In this article, we highlighted the stories of university student mentors who are involved in the Australian \\ Indigenous Mentoring Experience (AIME). The AIME program works with young Indigenous school \\ students, at primary and secondary school levels, to encourage continued participation in education and \\ to consider university as a viable life goal. The AIME program is explored from the perspective of the \\ university students who are selected to mentor young Australian Indigenous school students. Adopting a \\ narrative inquiry approach, the article presents richly descriptive insight into the motivations of these \\ mentors and highlights how this experience has impacted upon them. While the research presented \\ focuses on narratives of mentors, the data indicate that the AIME program employs an innovative \\ approach to mentoring that enhances cultural understanding for mentors.
}

\section{Keywords}

students, university, challenge, narratives, australians, indigenous, young, change, mentoring, connection

\section{Disciplines}

Education | Social and Behavioral Sciences

\section{Publication Details}

O'Shea, S., Harwood, V., Kervin, L. \& Humphry, N. (2013). Connection, challenge, and change: the narratives of university students mentoring young Indigenous Australians. Mentoring and Tutoring, 21 (4), 392-411. 


\title{
Connection, Challenge and Change: The narratives of university students mentoring young
}

\section{Indigenous Australians}

Sarah O'Shea, Valerie Harwood, Lisa Kervin \& Nici Humphry

University of Wollongong

\begin{abstract}
This article highlights the stories of university student mentors who are involved in the Australian Indigenous Mentoring Experience (AIME). The AIME program works with young Indigenous school students, at primary and secondary school levels, to encourage continued participation in education and to consider university as a viable life goal. The article explores this program from the perspective of the university students who are selected to mentor young Australian Indigenous school students. Adopting a narrative inquiry approach, the article presents richly descriptive insight into the motivations of these mentors and highlights how this experience has impacted upon them. While the research presented focuses on narratives of mentors, the data indicates that the AIME program employs an innovative approach to mentoring that enhances cultural understanding for mentors.
\end{abstract}

Keywords: Mentoring, Indigenous students, University access and participation, narrative inquiry ${ }^{1}$

\footnotetext{
${ }^{1}$ To cite this article: Sarah O'Shea, Valerie Harwood, Lisa Kervin \& Nici Humphry (2013) Connection, Challenge, and Change: The Narratives of University Students Mentoring Young Indigenous Australians, Mentoring \& Tutoring: Partnership in Learning, 21:4, 392-411, DOI: $10.1080 / 13611267.2013 .855863$
} 


\section{Introduction}

Mentoring has become a popular mechanism by which to increase access and participation in higher education, with some universities working with university students as mentors. In this paper, we report on an Australian mentoring program that is extremely successful in engaging young Aboriginal and Torres Strait Islander peoples. This program is instructive for new approaches to mentoring young people from groups traditionally underrepresented at university. In this sense, there is a great deal to learn from this innovative program that is engaging and surmounting barriers for young people in Australia.

Innovative engagement programs have become increasingly important given the changes in university demographics. This is evident internationally (James, Krause \& Jennings, 2010; Crozier, Reay, Clayton, Colliander \& Grinstead, 2008) with general enrollments increasing by $53 \%$ in 1 decade and in 2010, constituting just over 150 million enrollments worldwide (Altbach, 2010). This increase has been assisted by the establishment of national targets, some of which are designed to increase the participation and access of certain student cohorts. For example, within Britain the late 1980s heralded a move to mass participation in the Higher Education sector culminating in New Labour's 2001 promise of 50\% participation for all 18-30 year olds by 2010 . In Ireland, the target focuses on mature age students and the aim is to increase their number to 25\% of the total full-time entrants by 2015 (Fleming, 2002). By 1989, Australia had already

achieved this goal (Scott, Burns \& Cooney, 1996) but in 2009, the Australian government 
introduced more ambitious targets, aiming that by $2025,40 \%$ of all $25-34$ year olds will have a university degree and that by $2020,20 \%$ of all students will be derived from low socio-economic [SES] backgrounds.

While this "open door" to university can be regarded as offering an opportunity to change life circumstances, there is also a need to make sure that this access is not simply a "revolving door" (Blythman \& Orr, 2001-2002, p. 232). Across the Australian university sector, noncompletion or student dropout consistently exceeds $20 \%$ of the total student population and $22.4 \%$ of the population leave in the first year of study (Lukic, Broadbent, \& Maclachlan, 2004), attrition that can be further delineated by the types of students who are choosing to leave university. Significantly, higher proportions of Indigenous $^{\mathrm{i}}$ and non-metropolitan students entertain thoughts of departure when compared to their non-Indigenous or urban cohorts (ACER, 2010). The report, How Young Indigenous People are Faring (Dusseldorp Skills Forum [DSF], 2009) includes research on a decade of statistics (1996-2006) to highlight the rapid decline in Indigenous student participation after compulsory schooling. While the retention and participation of Indigenous school students has increased across the decade, from 35\% in 1996 to $44 \%$ in 2006, such increases are not apparent in further education sector. Currently there is a higher proportion of the school leaver age group amongst the Indigenous population and yet levels of tertiary education participation remain consistently low (DSF, 2009). ${ }^{\text {ii }}$

Internationally, participation for Indigenous people remains problematic with participation rates lower than those of the general population and other marginalized groups. Indigenous peoples from Canada's First Nations people (Richards \& Scott 2009; Orr, Roberts \& Ross, 2008) the US's Native American Indian people, Native Hawaiian and Alaskan Native people (Aud, Fox, \& Kewal Ramaniud 2010; Hunt \& Harrington 2010; Cherubini, Hodson, 
Manley-Casimir \& Muir, 2010), New Zealand's Maori and Pacific people (Madjar, McKinley, Deynzer \& van der Merwe, 2010; Durie, 2009), are all significantly underrepresented in higher education. These global trends link with intersections between race and poverty (Orr et al., 2008; James, 2008; Hunt \& Harrington, 2010) and are compounded by very low secondary education completion rates (James, 2008; Orr et al., 2008), as well as the significant numbers of Indigenous people living in remote areas (Orr et al., 2008; Altbach, Reisberg \& Rumbley, 2009); all factors that exclude many Indigenous people from even attempting university participation. International approaches to addressing this gap include increasing financial support to certain student cohorts and the establishment of separate college/universities for particular groups of Indigenous people. Examples of these include U.S. Tribal colleges and universities, the Canadian First Nations University (James, 2008), Mexican ”intercultural universities" (Altbach et al, 2009, p. 49) and Wananga in New Zealand, which are similarly based "around indigenous world views and tribal knowledge but also addressing contemporary ... society" (Durie, 2009, p. 5).

Within Australia, reasons for the educational disparities between Indigenous and nonIndigenous are manifold and similarly reflect a range of social, cultural and economic imperatives. Sarra (2011) argued that there is a pervasive "mindset" within the Australian schooling system, that is quietly accepting that "Indigenous underachievement in schools ...[is] somehow 'normal' or 'given"” (p. 161). Sarra (2011) pointed to a range of factors that indicate this "mindset" including a general "apathy" on the part of educationalists about poor student attendance, little development of strong Indigenous educational leadership and the lack of systematic analysis of Indigenous student performance (p. 161). In this paper we will discuss how one grass roots organisation that, via a mentoring program, uses links to university to disrupt this "mindset". Through regular engagement with Indigenous school students over an extended 
period, the Australian Indigenous Mentoring Experience [AIME] program aims to encourage students to complete their schooling and also, consider further education opportunities. In this project, the researchers examined the mentoring ${ }^{\mathrm{iii}}$ relationship between university students (both Indigenous and non-Indigenous) and the Indigenous school children they mentor. The focus of the paper is on the university students who have volunteered to participate as mentors. The narratives of these university students indicate how outcomes of this mentoring relationship can be explored on a number of levels, effecting change both personally and publically.

\section{Mentoring as a Means to Engage}

Reporting on work in the United Kingdom, Colley (2003) identified how there is an increasing trend to use mentoring schemes as a means to engage young people in work and education. This type of "engagement mentoring" targets youth who may be socially excluded or at risk of becoming so. Colley defined the roles of mentors in such a program "... as that of transforming young people's attitudes, values, behaviours and beliefs - in short, their dispositions..." (p. 79). There is little disagreement in the literature about the possible benefits of mentoring, which is perceived as having a positive impact on the social and educational outcomes of young people (Dondero, 1997; Freedman, 1993; McGowan, Saintas \& Gill, 2009; Rogers, 2011), however assessing the success of these mentoring programmes for both the mentees and mentors is another matter. Assessment is not straightforward since there are a number of difficult to measure soft outcomes for both parties (Rogers, 2011). It is more often the hard outcomes such as gaining employability and/or entering education that count for policy makers and funding sources (Colley, 2003), but many outcomes relate more closely to the development of “...self- esteem, problem solving, decision-making and general life skills" (MacCallum, Bellman \& Palmer, 2005, p. 2). 
This view of assessment refers in particular to programs designed to re-engage young people with the workplace and gain employability, McGowan et al (2008) adopted the broader term social mentoring, which recognised the importance of establishing an emotional connection with the mentee. These authors proposed that social mentoring is more informal and essentially "seeks to bring about a change in the social status of the individual" (McGowan et al., 2008, p. 627). In fact it is the impact of mentoring on the social and cultural capital of young people that perhaps provides the best indication of the possibilities offered by this intervention within the higher education domain.

A preliminary analysis of the literature indicates that while there is a proliferation of research on mentoring programs, this tends to focus on individual programs and so is contextually bounded (Chuang, Thompson \& Schmidt, 2003; Jacobi, 1991; MacCallum et al, 2005). The introduction of mentor programs continues to increase in the higher education sector (Chuang et al, 2003) but relatively little empirical research explores this phenomenon in terms of mentor's motivations and/or the personal benefits derived from involvement (Beltman \& Schaeben, 2012; Jacobi, 1991; Johnson, Rose \& Schlosser, 2007). Within the higher education sector, a body of research explores mentoring relationships between Faculty members and students (see for example: Chuang et al, 2003; Komarraju, Musulkin \& Bhattacharya, 2010; Lechuga, 2011) and also those between existing and commencing students (Beltman \& Schaeben, 2012; O’ Shea, 2012; Stanley \& Lapsley, 2008). However, there is a dearth of material related to cross-sectorial mentoring amongst peers such as young undergraduate university students and high school students.

Mentoring programs can be regarded as one approach to providing insider information: a means to inform a mentee's habitus or the ways individuals are disposed to behave and react 
based on cultural affiliations and understandings. Understood as the combination of an individual's biography, sense of identity, personal traits, cultural background as well as their personal beliefs, values and perspectives, qualities of habitus are not necessarily uniquely determined and instead may be informed by the "social" and "collective" (Bourdieu \& Wacquant, 1992, p. 126).

The AIME program can be described as a social mentoring program that recruits university students to befriend Indigenous school students and provide both advice and personal support to mentees. AIME establishes a safe and supportive connection thus enabling the most productive outcomes to occur, as Colley (2003) explained "mentoring... aspires to create a human bond" (p. 32). Whilst some mentor relationships do develop on an informal basis, this is the exception and so it is necessary to create the opportunity for such connections. The AIME organisation sits outside the higher education system, funded independently as a charity, enabling AIME to work across institutions. The program is positively impacting on both school completion rates and also, university admissions, the high school completion for AIME students was $88 \%, 36 \%$ of which gained entry to university in 2011 (AIME, 2011).

AIME has a multi-pronged approach to retaining students within the school system and encouraging transition to university. Interaction with the mentees is conducted through two avenues: Learning Centres that are staffed by volunteers and connection with local high schools. At the Learning Centres, school children in both primary and early high school years attended after school sessions designed to provide support in relation to schoolwork and afternoon activities. In the high schools, Indigenous students are offered the opportunity to come oncampus at the local university and participate in a Year 9 Interactive program and a Year 10 Leadership program. In this way, AIME can be regarded as creating what Freedman (1993) 
termed a mentor-rich setting meaning that a large cohort of individuals with varied backgrounds but similar intents are co-located.

The AIME program offers up to 60 hours of additional support for Indigenous high school students in Years 7-12 (www.aimementoring.com). According to the latest Annual Report (2011), AIME supported 789 Indigenous high school students in 2011; this was a 49\% increase from 2010 numbers. Currently, AIME recruits mentors from 10 university sites across faculties and degree programs. By 2016, AIME plans to link 1,700 university mentors with 2,800 indigenous school students across 20 university sites throughout Australia.

\section{Methodology and Context}

\section{Context and participants}

At the research site, AIME initially partnered with five local high schools (2008), expanding in $2010(\mathrm{n}=7)$, and again in 2011 to a total of ten High Schools. Three Learning Centres are operating in the local community; two at local High Schools and one at a local Aboriginal Learning Centre. In 2011, this university location had one of the highest numbers of mentors to assist in the program $(n=190)$ with an equally high number of mentees $(n=120)$. The number of volunteer mentors was of particular interest to this study as we hoped to explore their personal reasons for becoming involved with the program. Mentors were invited to work with the research team to create a digital story about their motivation for involvement in AIME ${ }^{\text {iv }}$. In 2011, eight mentors participated in structured digital story workshops to create these artefacts. In addition, each mentor participant agreed to be interviewed about involvement in the program. Table (1) provides a snapshot of the mentors who participated.

\section{Methods and Design}


The data presented in this article is derived from these in-depth interviews. While mentoring is frequently assumed to be a more feminine activity, only marginally higher numbers of females volunteered to become AIME mentors at this campus in 2011. Recruitment of participants reflected this gender imbalance with 3 males and 5 females. The research participants reflected diverse mentor backgrounds; including a range of disciplines as well as cultural and ethnic backgrounds. While there were no restrictions in relation to mentoring and level of study, the majority of university participants in the AIME program and indeed in this research, were all studying at undergraduate level.

We were interested to explore what it was that this cohort gained from their involvement and indeed, what prompted them to volunteer. The semi-structured qualitative interviews were conducted both prior to mentors involvement and after involvement with the program. The interview questions were piloted with an AIME mentor who was also completing an honours project in conjunction with this research. The interviews were framed as conversations and so developed fluidly, with questions providing a starting point to this conversation. These conversations explored a number of themes including reasons for participation, expectations about the program and reflective commentary on involvement; the initial questions asked included the following:

Interview Pre: Semi Structured Questions

1. Have you volunteered to mentor with AIME before?

2. Why did you decide to volunteer for AIME this time?

3. What do you hope to get out of volunteering for AIME?

4. What do you expect to happen due to your involvement with AIME?

5. What will your involvement bring to AIME?

6. What do you expect the young people of AIME to be like?

7. What do you expect the AIME programme to be like? 
Interview Post: Semi Structured Questions

1. Have you volunteered to mentor with AIME before?

1(a) If so, was there a difference in your experience between the first and second experiences?

1(b) Why did you decide to volunteer for AIME for a second time?

2. What did you get out of your involvement with AIME this year?

3. What were you able to contribute to the AIME programme?

4. How do you see the young people of AIME now you have been involved with them?

5. What do you think of the AIME programme after experiencing it?

6. What do you see as the benefits of the AIME programme - for mentors? - for mentees?

Four of the participants participated in two to three interviews, one conducted just prior to the commencement of the AIME program, informal interviews during the digital story workshops and then a final interview at the conclusion of the AIME mentoring sessions. The in-depth data derived from this process revealed two interrelated areas of significance - motivational and relational aspects of mentor involvement.

\section{Methodology}

This study was informed by narrative inquiry, which recognises the significance of subjective experience when exploring social processes, exploring how people enact their life on a micro, as opposed to a macro, level (Merrill, 2004). We considered narrative inquiry to be a plausible way to capture and share the stories of these mentors through both their creation of digital text and also within the interviews. While the 250 word narrative script of the digital story was created in the researcher-led workshops, the mentors brought other texts to the setting, akin to field texts, most notable through the image selections that were made. In addition, the interviews were deliberately open-ended encouraging the mentors to engage in extensive narrative reflection as they each told stories relating to their participation with the program. 
Reliability and credibility were established by using multiple data sources and team member checking, consultation with participants that used multiple 'angles of scrutiny' (Harwood \& Rasmussen, 2007). The study design enabled us to cross-check interpretations with participants, which was important for analysis of digital stories. While there was a small sample size, the different data modalities (one-to one interviews, group discussion during digital story workshops, observations by three team members, digital stories) provides a depth of data for cross-reference results and ensuring the credibility of interpretations.

The process of narrative inquiry “...revolves around three matters: the field, texts on field experience, and research texts which incorporate the first two and which represent those issues of social significance that justify the research" (Connelly \& Clandinin, 1999, p. 34). The researchers perceived the unique combination of digital stories and in-depth interviewing as a way of recording these experiences. Narrative accounts are recognised as supporting "vicarious experience" as they typically emphasise time, place and person and the relationships among these (Stake, 1995, p. 87). As Middleton (1998) further justified:

When the stories of real people are positioned inside the educational and social theories we study... they offer an alternative to textbook presentations of these theories as typologies or flat maps. (p. 24)

In the sections that follow, these "alternatives" are described by drawing on the narratives of the mentors themselves, presenting a perspective that is both richly descriptive and also, grounded within student experience. In the discussion that follows we focus on the three key themes addressed by the interview questions: (a) reasons for getting involved in the AIME program, (b) expectations about the program and its participants, and (c) narratives of making connections with young Indigenous mentees. Whilst other themes did emerge during the 
interview conversations, these require further validation and explorations and so will form the basis for future interviews.

\section{Discussion}

Reasons for Getting Involved

AIME to me is basically family. It has given me the seeds to life... (Paul)

Participation in AIME had important outcomes for mentors. For Paul, an indigenous mentor, participation provided a stabilising force within the university environment, his narrative charting his own difficult relationship with university. This relationship turned out to be pivotal, since despite encouragement from friends and family, he nearly discontinued his studies after one year: went to uni just to satisfy the parents because they were so proud of me and ... I wasn't really showing up to classes and ... my thoughts were, I'm out of here just gave everything up for a labouring job and life's easy.

Paul's plans to leave were thwarted when a Student Support Officer encouraged him to persevere and suggested volunteering with AIME. Paul viewed this participation as doing "something for our people". While Paul's motivations are linked to his identification as an Indigenous person, perceiving AIME as offering a sense of community or family network is not limited to this participant. Yvonne, from a non-indigenous background for example, referred to AIME in terms of the familial and described how both the mentors and mentees alike experienced this collectivity:

It's a family environment, even if you're not family like I find people are kind of just joining up, like kids that just know each other from different schools, they're all from different schools but they kind of come together and ... it's a whole family. 
Undoubtedly, involvement with AIME is negotiated in a personal sense, with participation more than simply turning up to sessions and dispensing advice. Each of the mentors referred to AIME as facilitating connection. For young Indigenous people these connections proved to be vital to developing an imagination of university that the young person can envisage himself or herself entering. That the mentors acknowledged and actively worked toward these connections is of great importance.

References to connection were also apparent in mentor perceptions of AIME as a means to engage with Indigenous cultures and to better understand these cultures. AIME was regarded as a bridge between Indigenous and non-Indigenous cultures, a safe space to build a relationship in a landscape where not many of these spaces exist. Toni, for example, explained how the impetus to join AIME was derived from a desire to gain more "knowledge" of a culture that seemed to remain somewhat invisible in contemporary Australian society. For Toni, acquiring this knowledge was important to her sense of self and recognition that understanding Indigenous culture is fundamental to an Australian identity:

I don't want to be an ignorant person and I don't feel like I have any prejudices at all...I just wanted to personally come into closer contact with it so I understood for myself what it meant, rather than just - a lot of the ways that Indigenous people are treated in Australia it's very distant. I just don't think that's helpful and I just don't want to be ignorant about it.

Two of the other mentors, Helen and Colin, described how AIME enabled a "connect" with the local Indigenous community. Helen explained how it was a means to get “...involved in things and it's just something I'm very sort of personally passionate about." Equally, Colin defined his involvement in cultural terms explaining how he "...wanted to get some experience on an 
Indigenous culture...in order to see a different, like a different culture compared to what I'm used to back home."

The wider implications of participating in the program were reflected upon by a number of the participants; in Roger's case this sense of connection and belonging manifested itself when he was referred to as an "Elder" by one of the students in the Learning Centre. In the excerpt below Roger recognises the value of this status within the community and highlights the sense of unexpected pride that such a title evoked within him:

When I was at one homework centre in particular they actually called me an Elder - that was really weird and interesting. So that sort of accomplishment and pride from being involved...I was brought into an Indigenous place and was treated as an Elder ... getting treated that way, it's nice.

The AIME organisation initiated a space for this connection to occur, a connection not only between the mentors and the mentees but also between mentor/mentor and mentee/mentee. AIME not only succeeds in bringing together Indigenous people from all over the locality in a neutral space but also, the mentors described unexpected opportunities for social interaction.

Five participants indicated that AIME negotiated a space for them to meet other students outside of their disciplines and Faculties. This was perceived as an unexpected but welcomed benefit to participation, as this type of connection within the university landscape was limited. Emma, a North American exchange student, explained how her involvement enabled her to feel a part of a "little community" whilst Toni perceived this connection as being the fundamental tenet of the program rather than the educational outcomes. This opportunity for connection also extended to the mentees, with the development of a relationship with the young 
people another key theme to emerge in the interviews. The following section explores the nature of this relationship as well as comparing the expectations and reality of working in the program.

\section{Countering expectations, assumptions and stereotypes}

Stereotypical notions of Aboriginality are extremely problematic and countering these is of great significance to addressing discrimination of Indigenous peoples in Australia (Purdie, Dudgeon \& Walker, 2010). The mentors' narratives revealed both the erroneous viewpoints that individuals can have as well as the learning and self-discovery that participants underwent as mentors in the program.

The mentors all reflected in some depth about the range of expectations they had about the program and what they actually encountered. This information was particularly captured in the interviews with the first-time mentors, who were all relatively new to the program. Toni expressed surprise at "...how non-Indigenous they seemed". When prompted to elaborate she explained:

I thought they would look more Aboriginal which is stupid. I mean, my mentee looks like a white, shy Australian girl. She really doesn't look Indigenous at all.

Toni explained she is a "middle-class white person... [who] went to a privileged school" as justification of her lack of knowledge on Aboriginal Australia (which is in itself is an extremely problematic rationale, Sarra, 2011). She explained that she had not had much contact with the local Aboriginal community and was surprised to encounter her mentee as "just normal, like I could be talking to any other kid from the local feeder High School". The term "normal" is also extremely problematic, and while we are restricted here in our discussion, we wish to note the colonizing assumptions that appear to lay beneath this "just like us" description. 
Perceptions about appearances of mentees were not limited by cultural or social background, Paul, who identifies strongly as an Indigenous young man, also admits that he “...was expecting Aboriginal people; the perception of Aboriginal people, as in black". Indeed, for Paul, working with the young mentees led him to consider questions about his own appearance and whether he would be considered as Indigenous by others: "I know I'm Indigenous, but then am I really accepted as Indigenous. I still have that battle with myself, am I accepted?" On one level, Paul's exploration of assumptions around the mentees' appearance exposes misgivings and insecurities about his own personal cultural identity but equally, his statement revealed the embedded nature of stereotypical images and perceptions of Indigenous peoples within Australia.

The potential that involvement in the program has for redefining perceptions of Indigenous people and the possible ripple effect that this involvement can have was also noted by Andrea:

I think some of the mentors that do come into the program have ideas about Indigenous people that may not be correct...They get the chance to engage with that young Indigenous person and find that the rumours aren't true ...Then they change those ideas not only with themselves but also with their friends when they go home.

Andrea described how just wearing her AIME T-shirt "opens up" conversations which dispel the myths around "young Indigenous people, it's not what they hear on the news about, they're not always the vandals or they're not always the kids getting in trouble. There are lots of good kids...". 
The mentors also reflected upon the expectations they held about the possible behaviours of the children both in the Learning Centres and the on-campus programs. For newcomers, like Emma, there was initially mild trepidation about ability to keep the young mentees on task and focussed but in the second interview she explained "... getting them to actually do it wasn't as hard as I thought it was going to be". A number of the mentors expressed surprise at just how quiet the students were, Yvonne described how her mentees were "a bit hesitant" similarly Toni explained how her "kids are a little shy". For this reason, each of the mentors had to work hard at building rapport and relationship with the mentees and how they achieved this will be explored in the next section.

Making Connections with the young Indigenous mentees

The unique framework of the AIME program was instrumental for making the connections between mentors and mentees. The flexibility of the program assisted in supporting the mentors and the mentees in building rapport. Regardless of whether the mentees participated in on-campus sessions or attended a Learning Centre, there was relative fluidity around how interactions occurred. Toni described how in the Year 9 Interactive Program: “...you grab up your book. You have a bit of a chat. It usually takes a while for things to get started...”. Similarly, in the Learning Centres the structure was relaxed, or as Emma described "pretty organic". This framework enabled relationships to move beyond the traditional student/teacher arrangement that can often occur in traditional mentoring relationships. The informal nature of the program remained situated within a closely supervised setting led by Indigenous program leaders, but this still enabled mentors to move outside the teacher role and adopt the position of interested advisor or participant. 
In the on-campus component the structure can be characterised in terms of embodiment, further disrupting mentor-mentee relationships characterised by one person talking and the other listening. Instead, in AIME sessions both parties are actively involved in a physical sense by mutually participating in a range of activities. Paul explained how this level of engagement was unexpected:

I didn't expect to ever rap, I didn't expect I'd get up and do a play, I didn't honestly think I'd help an Indigenous student get a job.

Connections were premised on reciprocity where personal encouragement and emotional support seemed to be key characteristics of the mentor role.

Interestingly, within this formalised AIME mentoring structure, the mentors described the relative "freedom" their informal relationship bestowed upon their communications with the young people $\mathrm{v}^{\mathrm{v}}$ :

...we were also encouraged to ask questions at the beginning and then you can follow the conversation organically as it goes; it's not too scripted, but it's a basis for you to go from. Issues that you talk about, you learn more I guess... (Toni)

I get the chance to like, learn how to be friends with kids of this age... I don't have to have any discipline and it's just a friendship... (Andrea)

This flexibility and fluidity did not diminish the effort required to establish a connection, instead the emotional investment that the mentors put into the relationships was very apparent. Helen, an early childhood educator explained how she “...didn't expect to actually have to work that hard just to engage one on one with some of the children", similarly Toni described how "you do a lot of work" when building rapport with the mentees. 
Instead of being uni-directional, connections worked interactively with both mentees and mentors benefitting from participation. For Paul, learning was not only about the program and the actual practicalities of teaching or mentoring but were also inextricably tied up with his own sense of being Indigenous and what that means for family and community: "... I'm somewhat a test dummy for my family showing that it's achievable, I'm a test dummy for AIME in some sense." Similarly, Toni recounted how her approach to interacting with her mentee had engendered self-reflection on her part, highlighting how: "It was interesting watching myself negotiate how to do that positively rather than just being annoying."

Increased self-awareness was just one element of the learning that seemed to occur. Three of the mentors explicitly mentioned growth in their own confidence like Andrea whose involvement had led to "confidence to be like a role model for somebody" similarly Helen and Toni highlighted:

Just confidence in realising being able to connect with somebody is the most significant thing for me. (Toni)

...your own personal development of skills, of confidence, all of those sorts of things... (Helen)

The learning did not simply exist on a personal level; instead connecting with these young Indigenous students provided a clearer understanding of educational disadvantage, including the revelation that disadvantage continued to exist for young Indigenous peoples:

Only recently I found out that a lot of teachers were in the industry back in the seventies when you could actually kick an Indigenous student out just for a parent complaining that there was an Indigenous student at the school. So I didn't realise that they were still disadvantaged that badly... (Roger) 
These findings reveal the multi-faceted ways involvement as a mentor in the AIME program impacted upon individuals. The following discussion will explore some of the possible implications of this material and further considerations.

\section{Conclusion}

There were clearly numerous benefits for both mentor participation in AIME and for the young mentees, who have the opportunity for two-way engagement with university students. Such involvement for mentees also supports new ways to imagine university education. The imagination has been situated as of prime importance in educational equality, for 'it takes imagination on the part of the young people to perceive openings through which they can move' (Greene, 1995, p14). Taking cues from this perspective mentors provide valuable ways to assist Indigenous young people to perceive such openings. ${ }^{\mathrm{vi}}$ The importance of meeting a knowledgeable other is significant in a number of respects. Findings from our team's related study into imagination and university ${ }^{\mathrm{vii}}$ has identified that, for young people who have been educationally disengaged, it is how (and not whether) they imagine university that is crucial to their aspirations to continue with education. Young people interviewed revealed the extent to which they have not encountered university. One Aboriginal young woman poignantly explained: “I haven't actually really seen a university or been to one so it would be a bit hard to say what one would really look like" (Krissie, aged 16). Unlike the AIME mentees who have at least twenty opportunities to attend university campuses, this young woman had never had first hand experience of a university. Working with their mentors, the AIME mentees not only attend structured programs on campus but also have formal and informal recreational opportunities. For example, our team observed young people using breaks after the sessions to visit campus food outlets prior to returning to their schools. 
The findings from the mentor narratives provide insight into the positive impacts AIME has on mentee perceptions of university. The opportunity to meet with a knowledgeable other also provides opportunities to build both mentor and mentee cultural and social capital. It was not simply the case that mentee knowledge was improved via connections; it is of great significance for higher education retention that our findings show mentors such as Paul, an Indigenous young man, was encouraged to remain at university. Further in facilitating these connections, AIME is also supporting the development of social capital that not only directly benefits educational participation (for both mentees and mentors) but also benefits cultural awareness and arguably, has wider benefits for improving knowledge and understanding of Australia's Indigenous peoples by new generations of university graduates.

AIME carefully scaffolds this mentoring experience to maximise the learning opportunities for all involved. Mentors are recruited on-line and are required to attend formal training prior to their involvement, designed to provide communication skills, cultural understanding and insight into issues that some mentees may be encountering. This training is supplanted by regular debriefing sessions where mentors are encouraged to explore and articulate experiences with mentees. This opportunity to debrief is an integral and ongoing part of the program, welcomed by many mentors and is another facet to the learning acquired through participation:

I didn't know anything going into it so I guess it helped in that too because they would tell you... "Some kids might have this kind of situation happening in their home life and this might make them act a little bit like this". It wasn't like guidelines; it was just "This might be it so just approach everything with caution" kind of training. (Emma) 
Hence, while the program was regarded as informal and relatively "organic", AIME structure provided what can be termed as supported autonomy where mentors could respond to the mentees' particular needs and access support as required.

Our interviews revealed that mentors adopted a client centred approach, responding to the mentees' needs rather than imposing structures or activities onto participants. In AIME, the mentees were not acted upon but rather some practiced resistance in quite overt ways such as refusing to speak, listening to their IPods or not completing tasks. Mentors recognised these actions not as acts of deviance or defiance, but as acceptable actions on the part of young people finding personal place and space. This could be understood as an element of what Crozier et al. (2008) describe as the desire to "play". In their UK study of working class students, in order to encourage young people to consider higher education, they not only require the:

...strategies and resources and dispositions to "play" but also need the commitment and acceptance that the game is worth "playing" or as Bourdieu terms it "illusio". (Crozier et al. 2008, p. 168)

The mentors' experience within the university environment can be understood as providing for the mentees a means to access and recognise why this educational game is worth playing. Equally, enabling the mentee participants to move within the university campus and claim a space within this environment is a significant aspect of the AIME program. Rather than impose self-exclusion, AIME succeeds with its young participants by facilitating the mentees' recognition that they have a legitimate place in the university. As both Andrea and Helen explain: 
They get an idea that uni isn't as scary a place as what they've always believed it was. Hearing our stories, yes I would tell my mentee I have an exam coming up. I haven't had time to study or I had assignments, but I at least let her know about the good stuff at uni as well. The uni is a fun place. It's not that hard to get into. You just have to apply yourself for two years and then you're there. I think they get that foot in the door into uni. (Andrea)

I think that those kids who have come from families where no-one has previously gone to university and it is very easy obviously for university to be seen as a very distance alien place I think that's a great connection... (Helen)

The desire to build capacity was not limited to the mentees but also was demonstrated in how mentors were acculturated into the AIME organisation. Indeed, for Paul, AIME was not simply there for the mentees but was also a source of inspiration and learning for the mentors:

I really believe they set their program up for the mentees, but I strongly voice that the mentors get more that what the mentees do.

Paul eloquently sums up what a lot of the mentors allude to: how involvement with AIME effected change at a variety of levels. In Paul's own case, participation in AIME has not only provided support but also provided 'permission' for him to express his pride in being Indigenous and successful.

The AIME message 'Indigenous Means Success' (AIME, 2012) has come to life for these university mentors. Most of the mentors reflected on how their experience of being a mentor had affected them quite profoundly - this might be change in attitude or perspective but the changes 
were also articulated in a far more fundamental sense. Being an AIME mentor extended them personally and opened up possibilities to explore aspects of the self that they may not necessarily have considered as an option or relevant to them. The AIME program arguably offers an alternative field. The impact of this can be defined both in relation to the habitus of the mentor and the mentees, exposing the mentor to a new field but interestingly what the mentees arrive with is very much regarded as a valuable form of cultural and knowledge capital. A number of the mentors mention how their involvement with the program is tied up with their desire to understand and learn about Indigenous culture and community. Hence AIME redefines the field implicitly by valuing the mentees' cultural capital, a cause for celebration rather than something that should remain hidden or externalised. Significantly, for these mentors, the AIME program has succeeded in moving away from presenting the young mentees as deficit. In moving away from such a deficit view the university student mentors have had the opportunity to be involved in a mentoring program that engages the young Australian Indigenous high school students as embodied by a cultural identity that bestows success. In making the choice to connect and walk with AIME, participants, both mentors and mentees alike, are offered the opportunity to change, such changes manifested in their chosen educational trajectory or more fundamental beliefs and values. Our findings clearly point to the valuable experiences to be gained by university student mentors in programs such as AIME, and suggest this as a fruitful area for further research on the cross-cultural (two way) benefits of mentoring for university students. 
Table (1)

\begin{tabular}{|l|l|l|l|}
\hline Participants & Age & Cultural Background & Mentor status \\
\hline Andrea* & 20 & Non Indigenous & Returner \\
\hline Roger* & 23 & Non Indigenous & Returner \\
\hline Toni & 19 & Non Indigenous & First time \\
\hline Emma & 21 & Non Indigenous & First time \\
\hline Colin & 23 & Non Indigenous & First time \\
\hline Yvonne* & 26 & Non Indigenous & Returner \\
\hline Helen* & 27 & Non Indigenous & First time \\
\hline Paul & 22 & Indigenous & First time \\
\hline
\end{tabular}

*: Interviewed more than once 


\section{References}

ACER. (2010). Doing more for learning: Enhancing engagement and outcomes. Australasian survey of student engagement. Melbourne: Australian Council for Educational Research.

AIME. (2011). Annual Report. Retrieved from http://issuu.com/aimementoring/docs

Altbach, P. (2010). Access means inequality [Electronic Version]. International Higher Education, 61 (Fall). Retrieved from http://www.bc.edu/research/cihe.html.

Altbach, P. G., Reisberg, L., \& Rumbley, L. E. (2009). Trends in global higher education: Tracking an academic revolution (Report No. ED.2009/Conf.402/inf.5). Paris: UNESCO.

Aud, S., Fox, M., \& Kewal Ramani, A. (2010). Status and trends in the education of racial and ethnic groups. Washington, DC: National Center for Education Statistics.

Beltman, S., \& Schaeben, M. (2012). Institution-wide peer mentoring: Benefits for mentors. The International Journal of the First Year in Higher Education, 3(2), 33-44.

Blythman, M., \& Orr, S. (2001-2002). Joined up policy: A strategic approach to improving retention in the UK context. Journal of College Student Retention, 3(3), 231-242.

Bourdieu, P., \& Wacquant, L. (1992). An invitation to reflexive sociology. Chicago, IL: University of Chicago Press.

Cherubini, L., Hodson, J., Manley-Casimir, M., \& Muir, C. (2010). 'Closing the gap' at the peril of widening the void: Implications of the Ontario Ministry of Education's policy for Aboriginal education. Canadian Journal of Education. 33(2), 329-355.

Chuang, H. H., Thompson, A., \& Schmidt, D. (2003). Faculty technology mentoring programs: Major trends in the literature. Journal of Computing in Teacher Education, 19(4), 101-106.

Colley, H. (2003). Engagement mentoring for socially excluded youth: Problematising an 'holistic' approach to creating employablity through the transformation of habitus. British Journal of 
Guidance and Counselling, 31(1), 77-99.

Connelly, F., \& Clandinin, D. (Eds.). (1999). Shaping a professional identity. London, UK: Althouse Press.

Crozier, G., Reay, D., Clayton, J., Colliander, L., \& Grinstead, J. (2008). Different strokes for different folks: Diverse students in diverse institutions - experiences of higher education. Research Papers in Education, 23(2), 67-177.

Dondero, G. (1997). Mentors: Beacons of hope. Adolescence, 32(128), 881-886.

Durie, M. (2009, June). Towards social cohesion: The indigenisation of higher education in New Zealand. Paper presented at the 2009 Vice Chancellors' Forum, Kuala Lumpur, Malaysia. Retrieved from http://akoaotearoa.ac.nz/community/mātaurangamāori/resources/pages/towards-social-cohesion-indigenisation-higher-education-newzealand.

Dusseldorp Skills Forum. (2009). How Indigenous young people are faring: Key indicators 1996 - 2006. A report about the learning and work situation of young Indigenous Australians. Canberra, Australia: Reconciliation Australia.

Fleming, T. (2002, March). Access and accessibility: where students and academy meet. Paper presented at the WERRC Women in Adult Education Conference: Building Islands or Bridges. University College Dublin. Retrieved from http://eprints.nuim.ie/991/.

Freedman, M. (1993). The kindness of strangers: Adult mentors, urban youth and the new voluntarism. Cambridge, England: Cambridge University Press.

Greene, M. (1995). Releasing the imagination: Essays on education, the arts, and social change. San Francisco, CA: Jossey Bass.

Harwood, V., \& Rasmussen, M. L. (2007.) Scrutinizing sexuality and psychopathology: a Foucauldian 
inspired strategy for qualitative data analysis. International Journal of Qualitative Studies in Education, 20(1), 31-50.

Hunt, B., \& Harrington, C. (2010.) The impending educational crisis for American Indians:

Higher education at the crossroads. Indigenous Policy Journal. XXI(3). Retrieved from http://indigenouspolicy.org/Articles/VolXXINo3/TheImpendingEducationalCrisisforAme $\underline{\text { rican/tabid/133/Default.aspx. }}$.

Jacobi, M. (1991). Mentoring and undergraduate academic success: A literature review. Review of Educational Research, 61(4), 505-532.

James, R. (2008). Participation and equity: A review of the participation in higher education of people from low socioeconomic backgrounds and Indigenous people. Melbourne, Australia: Centre for the Study of Higher Education.

James, R., Krause, K., \& Jennings, C. (2010). The first year experience in Australian universities Findings from 1994 - 2009. Melbourne, Australia: Centre for the Study of Higher Education.

Johnson, W. B., Rose, G., \& Schlosser, L. (2007). Student-faculty mentoring: theoretical and methodological issues. In T. Allen \& L. Eby (Eds.), The Blackwell handbook of mentoring: A multiple perspectives approach (pp. 49-69). London: Blackwell.

Komarraju, M., Musulkin, S., \& Bhattacharya, G. (2010). Role of student-faculty interactions in developing college students' academic self-concept, motivation, and achievement. Journal of College Student Development, 51(3), 332-342.

Lechuga, V. (2011). Faculty-graduate student mentoring relationships: Mentors' perceived roles and responsibilities. International Journal of Higher Education Research, 62, 757-771.

Lukic, T., Broadbent, A., \& Maclachlan, M. (2004). Higher Education Attrition Rates 1994 - 2002: A brief overview: Research Note No. 1. Retrieved from 
http:/heer.qaa.ac.uk/SearchForSummaries/Summaries/Pages/LTA117.aspx.

MacCallum, J., Bellman, S., \& Palmer, D. (2005). Mentoring as a context for developing motivation. Paper presented at the Australian Association for Research in Education Conference. Retrieved from http://www.aare.edu.au/05pap/mac05613.pdf

Madjar, I., McKinley, E., Deynzer, M., \& van der Merwe, A. (2010). Stumbling blocks or stepping stones? Students' experience of transition from low-mid decile schools to university. Auckland, New Zealand: Starpath Project, The University of Auckland.

Merrill, B. (2004). Biographies, class and learning: the experiences of adult learners. Pedagogy, Culture and Society, 12(1), 73-94.

McGowan, B., Saintas, P., \& Gill, K. (2009). On mentoring, social mentoring and befriending. AI \& Soc: Journal of Knowledge, Culture and Communication, 23, 613-630.

Middleton, S. (1998). Disciplining sexuality: Foucault, life histories \& education. New York: Teachers College Press.

Orr, J., Roberts, C., \& Ross, M. (2008). First Nations' post secondary education and training literature review and best practices: Leading towards recommendations for comprehensive post-secondary planning and evaluation framework for Mi'kmaw Kina'matnewey. Nova Scotia, Canada: Indian and Northern Affairs.

O'Shea, S. (2012). UStart: A peer designed and led orientation activity. E-Source for College Transitions, 9(2), 4-6.

Purdie, N., Dudgeon, P. \& Walker, R. (2010). Working together: Aboriginal and Torres Strait Islander mental health and wellbeing principles and practice. Canberra, Australia: Commonwealth of Australia.

Richards, J., \& Scott, M. (2009). Aboriginal education: Strengthening the foundations. Ontario,Canada: 


\section{Canadian Policy Research Networks.}

Rogers, R. (2011). Evaluating community-based interventions for young people: Measuring the impact of informal mentoring. Journal of Poverty and Social Justice, 19(2), 159-168.

Sarra, C. (2011). Strong and smart - Towards a pedagogy for emancipation. London : Routledge.

Scott, C., Burns, A., \& Cooney, G. (1996). Reasons for discontinuing study: The case of mature age female students with children. Higher Education, 31, 233-253.

Stake, R. E. (1995). The art of case study research. London: Sage Publications.

Stanley, D., \& Lapsley, J. (2008). Student mentors: Supporting new-to-course transition. Journal of Australian and New Zealand Student Services Association, 32, 46-60.

\footnotetext{
i The term 'Indigenous' is used in this paper to refer to the Indigenous peoples of Australia, inclusive of Aboriginal and Torres Strait Islander peoples.

ii Whilst nearly one in five Indigenous teenagers are not studying nor working, this figure increases to one in every three of young adults and $25-29$ year olds (DSF, 2009).

iii In this article we use Robert's (1998) definition that perceives a mentor as someone who may 'teach, guide, be a role model, coach, counsel, empower, nurture, provide friendship, encourage or display enthusiasm' (pp19-20).

iv Digital Storying refers to the creation of an individual multimodal, digital text that combines photos and voice, and is created through the use of computer video-editing software.

$\mathrm{v}$ This is an extremely important finding, and the focus of a separate paper on AIME mentoring and pedagogy. For reasons of space we cannot discuss this in this article.

${ }^{\mathrm{vi}}$ From research by Valerie Harwood, Imagining university education: The perspectives of young people impacted by low socio-economic statues and disengagement from school (Australian Research Council, DP110104704)

${ }^{\text {vii }}$ Australian Research Council, DP110104704. This study forms part of this team's larger program of work on educational and social inclusion.
} 